\title{
Cryptogenic late-onset epileptic spasms
}

INSERM

\section{Source}

INSERM. (1999). Orphanet: an online rare disease and orphan drug data base.

Cryptogenic late-onset epileptic spasms. ORPHA:163708

Cryptogenic late-onset epileptic spasms is a rare epilepsy syndrome characterized by late-onset (after 1 year old) epileptic spasms that ocurr in clusters, associated with tonic seizures, atypical absences and cognitive deterioration. Language difficulties and behavior problems are frequently present. EEG is characterized by a temporal, or temporofrontal, slow wave or spike focus combined with synchronous spike-waves and no hypsarrhythmia or backg round activity. 